\title{
Improving Children's Emotional Health through Installing Biowalls in Classrooms
}

\author{
A-Young Lee ${ }^{1}$, Ha-Ram Kim², Hyuk Joon Kwon ${ }^{3}$, Soo-Young Kim³ ${ }^{3}$, and Sin-Ae Park ${ }^{4} 5^{*}$ \\ ${ }_{1}^{1}$ Post-doctoral associate, Department of Horticulture and Landscape Architecture, National Taiwan Univ., Taipei, 10673, Taiwan \\ ${ }^{2}$ Master's degree graduate, Department of Horticultural Therapy, Graduate School of Agriculture and Animal Science, Konkuk Univ., \\ Seoul 05029, South Korea \\ ${ }^{3}$ Senior researcher, National Institute of Biological Resources, Incheon 22689, South Korea \\ ${ }^{4}$ Assistant professor, Department of Systems Biotechnology, Konkuk Univ., Seoul 05029, South Korea \\ ${ }^{5}$ Assistant professor, Department of Bio \& Healing Convergence, Gradute School, Konkuk Univ., Seoul 05029, South Korea
}

\section{ABSTRACT}

Background and objective: The physical environment where children spend most of their time is closely associated with their emotional development. To improve the emotional health of children, the introduction of natural elements in the indoor space has been suggested, the benefits of which have been shown in preliminary studies. This study aims to examine the effects that a biowall - a wall installation - in a classroom has on the emotional health of children in kindergarten.

Methods: A total of four biowalls were separately installed in four kindergarten classrooms at a school in Seoul, South Korea, and the 60 children in these classrooms participated in the study. We assessed the children's emotional intelligence (via an Emotional Intelligence Rating Scale), resilience (via the Devereux Early Childhood Assessment), and eco-friendly attitudes (via the Children's Attitudes Toward Scale) before the installation of the biowalls and then again 3 months later. Results: The children's emotional intelligence, resilience, and eco-friendly attitudes had been significantly improved after the installation of the biowalls $(p=.01)$. The sub-categories of the children's emotional intelligence and resilience were also significantly improved $(p<.001)$.

Conclusion: This study demonstrates the potential of biowalls-as an indoor environmental factor-in promoting the healthy emotional development of children. By bringing natural elements into indoor classroom settings, biowalls appear to increase children's direct/indirect contact with nature. To extrapolate the results of the study to the general population, future studies should be conducted with broader age groups.

Keywords: Biophilic design, classroom environment, emotional intelligence, nature exposure, wall-greening

\section{Introduction}

Children's emotional development is closely associated with the physical environment in which they spend most of their time (Ferguson et al., 2013). Studies have shown that children prefer spending time in natural green spaces, such as grassy fields or parks (Korpela, 2002; Moore, 1986). When one feels connected to nature, they may experience a reduction in stress and express positive social and eco-friendly behaviors, among many other benefits, which contribute to enhancing an individual's quality of life (Collado and Staats, 2016; Howell et al., 2013). Since children are sensitive and receptive to nature's benefits, providing a connection to nature during their preschool years is exceptionally critical (Kahn and Kellert, 2002; Phenice and Griffore, 2003; Zhang et al., 2014).

Children living in the urban environments of modernized cities barely have sufficient opportunities to experience and

The research was funded by grant no. NIBR202013102 from the National Institute of Biological Resources in Korea.

Received: October 20, 2020, Revised: December 14, 2020, Accepted: December 27, 2020

First author: A-Young Lee, danapre0302@gmail.com, (1) https://orcid.org/0000-0001-5719-5548

*Corresponding author: Sin-Ae Park, sapark42@konkuk.ac.kr, (1) https://orcid.org/0000-0003-1367-8825 
play in nature (Bailie, 2010; Hofferth, 2009). In today's society, children spend most of their time indoors during school hours, interacting with artificial objects, textbooks, and toys (Bailie, 2010; Phenice and Griffore, 2003). In South Korea, for example, preschool children spend approximately 22.7 hours indoors during the weekdays and only experience the outdoors for an average of 34 minutes each day (Yoon et al., 2020). Meanwhile, 12\% of children in the UK (1.3 million) have not even visited a natural environment (e.g., park, forest, or grassland) within the last year (Natural England, 2016). Making matters worse, this trend of children spending huge amounts of time indoors has been increasing from 1975 to 2015 (Mullan, 2019). This highlights the importance of ensuring a high-quality classroom environment for children that lack nature-oriented indoor spaces (van den Berg et al., 2017). Studies illustrate that children experience different states of development and well-being according to the design of their learning environment, or classroom, where they spend so many hours of their daily routine (Evans, 2006; Leung and Fung, 2005).

Placing plants in a learning environment to combine nature with indoor spaces, for example, can help achieve this goal, and has gained popularity in recent years. It is also known as biophilic design (Gillis and Gatersleben, 2015), which relies on the assumption that plants positively contribute to the quality of an indoor environment (e.g., through air-purification and climate control) due to the emotional responses that result from their presence (Deng and Deng, 2018). Direct/indirect exposure to nature via indoor plants may not only benefit one's living environment but also benefit an individual's health in physical, cognitive, social, and emotional respects (Pegas et al., 2012).

Choi et al., (2016) reported that installing a minimum number of plants in an indoor space could lead to emotional stability and recovery, as their subjects showed improvements that were evident in their brain waves and heart rates. For children and students, studies have found that installing plants in a classroom improves physical health, motivation for academic achievement and concentration, while reducing problematic behaviors (Daly et al., 2010; Doxey et al., 2009; Park et al., 2008). For example, adding indoor gardens to urban elementary school classrooms creates opportunities for children (who previously lacked access to nature in their classrooms) to interact with and experience nature, which increases their attention spans and emotional intelligence (H.H. Kim et al., 2020; van den Berg et al., 2017). Similarly, a study investigated the effects of placing plants in classrooms by utilizing biowalls. The study included 170 children (7-10 years old) from four classes, and the researchers discovered that the installation of biowalls increased the children's attention span and encouraged them to positively evaluate the classroom environment after four months (van den Berg et al., 2017).

An example of biophilic design, biowalls are a creative alternative to containerized plants in a classroom environment (Manso and Castro-Gomes, 2015), and there are numerous advantages of utilizing them in an indoor space. Often referred to as vertical planting systems, biowalls need less maintenance than conventional containerized plants/gardens due to their self-supportive drip irrigation systems. Also, the vertical presentation of the plants on biowalls demands less space than plants displayed in containers. A biowall has a large green side across its surface, which contains space for dense plant placement. This facilitates the unique sensation and experience of nature, creating a substantial psychological impact on viewers. Another characteristic of biowalls is their ability to purify the air, while moderating the temperature and humidity in the space's micro-environment. Furthermore, biowalls can offer an opportunity for environmental education, aesthetic value, a resting space, and emotional/psychological stability to observers (van den Bogerd et al., 2020).

Thus far, there has been a lack of studies investigating the effects that indoor plants have on children's emotional development. Therefore, this study examines the effects of biowalls on the emotional health of children in kindergarten, as they spend most of their time in a classroom environment.

\section{Research Methods}

\section{Participants and Experimental Design}

To recruit participants for the study, the researchers visited D kindergarten, which is located in Geumcheon-gu, Seoul, South Korea. Before installing the biowalls, the re- 
searchers explained the study's purpose, schedule, and the precautions involved to both the young children and their teachers at the kindergarten. Of the children, 60 agreed to participate in the study, and for those who were willing, their parents completed a form, indicating their child's agreement to participate.

The researchers surveyed the demographic information (e.g., gender, age, etc.) that had been provided by the children's parents, which showed that the average age of the children was $4.0 \pm 0.8$ years. Twenty children per each age group of 3, 4, and 5 years old were selected to from experimental group. Overall, the male to female ratio was $0.88 ; 46.7 \%(\mathrm{n}=28)$ of the participants were boys, while $53.3 \%(\mathrm{n}=32)$ were girls. The study used a one-group pre-test/post-test design, with no control group.

\section{The Installation of the Biowalls}

The plants used in the biowalls were native to South Korea, and included the broad flat rock tree (Maesa japonica [Thunb.] Moritzi \& Zoll) and the marlberry (Ardisia japonica). Plants with evergreen growth characteristics in the shade were selected for this study, to enable easier maintenance and management of the biowall. In addition, these plants are known for providing the effects of removing fine dust and purifying air (National Institute of
Biological Resources, 2018). The installation was completed on the walls of four kindergarten classrooms (Fig. 1). One biowall was installed per classroom, so four biowalls were installed in total (Biowall, Garden4u, Ansan, Korea). The areas of the biowalls were $222 \mathrm{~cm} \times 110 \mathrm{~cm}$, $150 \mathrm{~cm} \times 120 \mathrm{~cm}, 150 \mathrm{~cm} \times 123 \mathrm{~cm}$, and $148 \mathrm{~cm} \times 121 \mathrm{~cm}$, as they were modified to fit the sizes of the individual classroom walls (Fig. 1). The biowalls were equipped with an air ventilation system, which circulated and propelled the fresh air that was released from the plants on the biowalls into the ambient air. Also, an automatic irrigation system was installed, which controlled the water, supplying an adequate amount to the plants. The children were at the kindergarten, where they were exposed to the biowalls, for an average of seven hours daily.

\section{Assessments}

To assess improvements in the children's psychological health, we measured their emotional intelligence, resilience, and eco-friendly attitude. The evaluation was conducted twice by the children as well as their teachers. The first evaluation occurred before the biowalls' installation and the second was conducted 3 months later. The children's emotional intelligence and resilience were evaluated by the teacher based on observations of their daily life, while

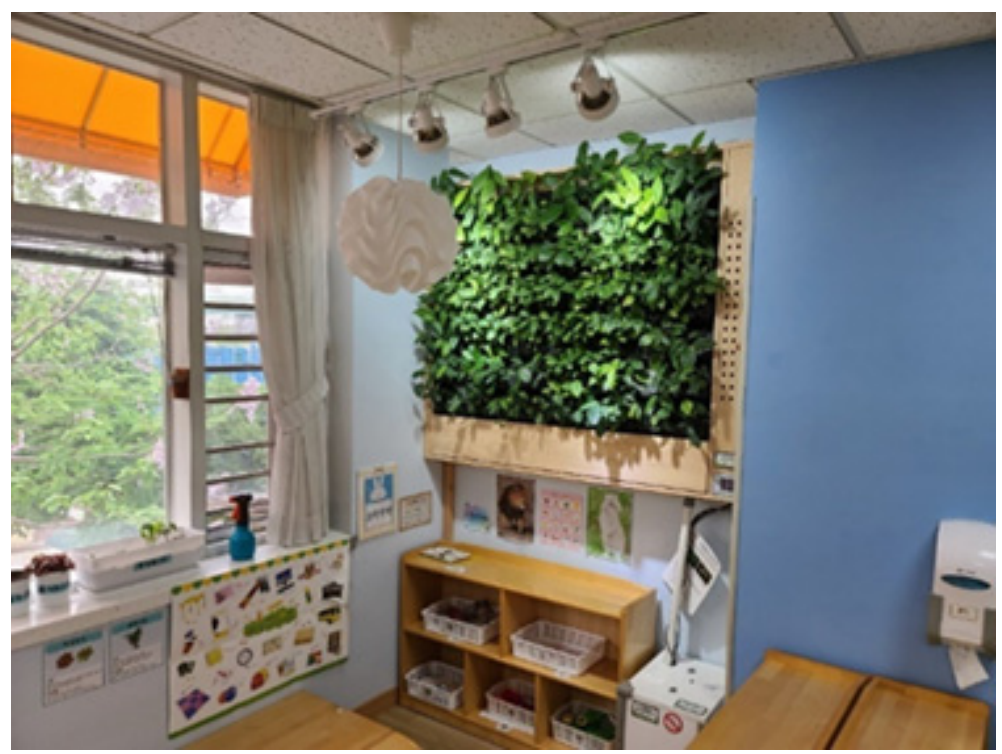

Fig. 1. This is an example of an installed biowall $(148 \mathrm{~cm} \times 121 \mathrm{~cm})$ and the plants that were utilized, which include broad flat rock trees and marlberry. 
the researchers asked the children questions regarding their eco-friendly attitude (i.e., a self-evaluation). The average time required for the assessment of each child was $20 \mathrm{~min}$.

\section{Emotional Intelligence}

Under the umbrella of social intelligence, emotional intelligence indicates an individual's mental capacity for realizing and describing various emotions, including their own as well as those of others (Lee, 2005; Salovery and Mayer, 1990). To evaluate the children's emotional intelligence, we used the Emotional Intelligence Rating Scale for Preschool Children proposed by Lee (2005) and developed under an emotional intelligence model (Salovey and Mayer, 1990). This scale is composed of 31 questions with four subcategories: Perceive Emotions (7 questions), Manage Emotions (8 questions), Facilitate Thought (9 questions), and Understand Emotions (7 questions). The total possible score of the scale ranges from 31 to 155; a higher score within this range indicates that the respondent has a higher degree of emotional intelligence. The Cronbach's coefficient for the emotional intelligence survey was measured at 0.90 (Lee, 2005).

\section{Resilience}

Resilience refers to an individual's mental capacity for handling and successfully adapting to adverse events during their lifetime (e.g., risk, stress, or trauma). To evaluate the children's resilience, we used the Korean version of the Devereux Early Childhood Assessment (Egeland et al., 1993; LeBuffe and Naglieri, 1999; Lee, 2002). The survey included 37 questions with four subcategories: Attachment (8 questions), Initiative (12 questions), Self-Control (7 questions), and Behavioral Problems (10 questions). The total possible score ranges from 37 to 185; a higher score indicates a higher degree of resilience. The Cronbach's coefficient for the resilience survey was measured at 0.85 (Lee, 2002).

\section{Eco-Friendly Attitude}

To evaluate the children's eco-friendly attitude, we utilized Children's Attitudes Toward Scale-Preschool version (CATC-PV) (Hur, 2001; Musser and Diamond, 1999). This scale is composed of 18 questions, with two subcategories:
Nature-Friendly Attitude (11 questions) and Environment Conservation Attitude ( 7 questions). The total possible score ranges from 18 to 72 ; a higher score indicates a more positive eco-friendly attitude. The researchers individually interviewed the children and ensured that the pictures used in the study were clearly understood. The Cronbach's coefficient for the emotional intelligence survey was measured at 0.75 (Hur, 2001).

\section{Satisfaction Survey}

We revised and tailored a satisfaction survey for the classroom environment (Park et al., 2016). The children, parents, and teachers participated in this modified satisfaction survey 3 months after the biowalls were installed. The survey consisted of two questions that related to their satisfaction after the biowalls were installed: (1) How satisfied are you with the environment? (5-point Likert scale), (2) Have the children experienced any positive changes (multiple responses)?

\section{Data Analysis}

To compare the children's measurements before and after the biowalls' installation, the paired samples t-test was conducted utilizing SPSS software (Version 25 for Windows; IBM corp., Armonk, NY, USA). For a reliability analysis, Cronbach's $\alpha$ coefficient was calculated to measure the reliability of this study's evaluation tools. Values of $p<.05$ were considered statistically significant. Finally, the children's demographic information and satisfaction with their classroom environment (after the biowalls' installation) was analyzed by utilizing Excel software (Office 2016; Microsoft Corp., Redmond, WA, USA).

\section{Results and Discussion}

\section{The Effects of the Biowalls on Children's Emotional Intelligence, Resilience, and Eco-Friendly Attitude}

After the installation of a biowall in their classroom, the children showed significantly improved resilience, emotional intelligence, and eco-friendly attitudes (Table 1, 2, 
and 3). Before the installation, the children's emotional intelligence score was $106.12 \pm 9.96$, but after 3 months with the biowalls their score was increased to $115.44 \pm 9.01$ $(p<.001)$. Comparing the children's four subdivided scores before and after the installation, they significantly improved after 3 months.

Similarly, a significant increase in the children's resilience score was observed after the installation $(p<.001$, Table 2). The children also showed improvement in the four subcategories for the resilience score: Initiative, Self-Control, Attachment, and Behavioral Problems were at a highly significant level of $p<.001$.

Also, compared to the scores before the installation, the children's eco-friendly attitude scores were high 3 months after the installation. The children's overall eco-friendly attitude score was increased from $55.32 \pm 6.98$ to $58.40 \pm 6.71$ (Table 3). Under the two subcategories for the eco-friendly score, the Nature Friendly Attitude improved, while Environmental Conservation Attitude did not significantly improve over the course of the study.

\section{Satisfaction Evaluation}

Table 1. The paired samples t-test comparisons of the children's emotional intelligence scores are illustrated below, including before the installation of the biowalls in the classroom and 3 months after

\begin{tabular}{crrr}
\hline Variable & Pre-test & Post-test & \multirow{2}{*}{$p$} \\
\cline { 2 - 3 } & \multicolumn{2}{c}{ Mean \pm SD } & $<.000^{* * *}$ \\
Emotional intelligence & $106.12 \pm 9.96$ & $115.44 \pm 9.01$ & $<.000^{* * *}$ \\
Perceive emotions & $25.09 \pm 2.86$ & $27.89 \pm 2.76$ & $.006^{* * *}$ \\
Manage emotions & $25.58 \pm 4.01$ & $27.21 \pm 4.01$ & $<.000^{* * *}$ \\
Facilitate thought & $24.05 \pm 3.08$ & $25.89 \pm 2.82$ & $<.000^{* * *}$ \\
Understand emotions & $31.40 \pm 3.36$ & $34.44 \pm 2.89$ & \\
\hline
\end{tabular}

Note. $\mathrm{n}=60$

${ }^{* *} p<.01, \stackrel{* * *}{p} p<.001$.

Table 2. The paired samples t-test comparisons of the children's resilience scores are illustrated below, including before the installation of the biowalls in the classroom and 3 months after

\begin{tabular}{cccc}
\hline Variable & Pre-test & Post-test & \\
\cline { 2 - 3 } & \multicolumn{2}{c}{$p$} & $<.000^{* * *}$ \\
Resilience & Mean \pm SD & & $<.000^{* * *}$ \\
Initiative & $95.19 \pm 11.49$ & $126.02 \pm 12.38$ & $<.000^{* * *}$ \\
Self-control & $32.52 \pm 5.98$ & $37.87 \pm 6.25$ & $<.000^{* * *}$ \\
Attachment & $17.27 \pm 4.39$ & $21.00 \pm 3.53$ & $<.000^{* * *}$ \\
Behavioral problems & $23.42 \pm 3.17$ & $26.31 \pm 3.85$ & $40.85 \pm 4.86$ \\
\hline
\end{tabular}

Note. $\mathrm{n}=60$

${ }^{* * *} p<.001$.

Table 3. The paired samples t-test comparisons of the children's eco-friendly attitude scores are illustrated below, including before the installation of the biowalls in the classroom and 3 months after

\begin{tabular}{cccc}
\hline Variable & Pre-test & Post-test & \multirow{2}{*}{$p$} \\
\cline { 2 - 3 } & \multicolumn{2}{c}{ Mean \pm SD } & \\
\hline Eco-friendly attitude & $55.32 \pm 6.98$ & $58.40 \pm 6.71$ & $.008^{* *}$ \\
Nature friendly attitude & $34.60 \pm 5.05$ & $36.72 \pm 4.57$ & $.015^{*}$ \\
Environmental conservation attitude & $20.70 \pm 3.51$ & $21.68 \pm 3.23$ & $.109^{\mathrm{NS}}$ \\
\hline
\end{tabular}

${ }^{\text {NS Non-significant }}{ }^{*} p<.05, p<.01$. 
The satisfaction evaluation conducted after the biowalls' installation revealed that $67.8 \%$ of the children were either "Satisfied" or "Very satisfied" with the classroom environment in their responses to the first question (Table 4). Regarding the second question about positive changes in the classroom environment, the highest rating among the children was "Feeling better" $(n=34,22.4 \%)$, followed by "Classroom was clean" $(\mathrm{n}=33,21.7 \%)$, and "Air was improved" $(\mathrm{n}=32,21.1 \%)$.

The teachers $(n=3)$ that responded to the satisfaction evaluation illustrated their satisfaction with the classroom environment (i.e., the addition of the biowalls) for the first question (Table 4). In the second question, the highest rating among the teachers was "Classroom was beautiful" ( $\mathrm{n}=2,66.7 \%$ ), followed by "Air was improved" $(\mathrm{n}=1,33.3 \%)$.

Similarly, most of the parents $(96.5 \%)$ that responded indicated that they were either "Satisfied" or "Very satisfied" with the biowalls in the classroom environment (Table 4), and many ( $\mathrm{n}=34,54.0 \%)$ said that the "Children became more interested in plants." Regarding the second question about positive changes in their children, the parents said that the "Children were emotionally stable" $(n=10,15.9 \%)$, "Environmental diseases were alleviated" ( $\mathrm{n}=5,7.9 \%$ ), "Children's expressiveness was improved" $(\mathrm{n}=3,4.9 \%)$, “Children's relationships with peers were improved" ( $\mathrm{n}=2,3.2 \%)$, "Children became more knowledgeable about plants" $(\mathrm{n}=2,3.2 \%)$, and "Children's concentration improved" $(\mathrm{n}=2,3.2 \%)$.

\section{Comprehensive Discussion}

Table 4. Satisfaction with installing the biowalls in the classroom

\begin{tabular}{clc}
\hline \multicolumn{2}{c}{ Environmental satisfaction } & $\mathrm{n}(\%)$ \\
\hline & Very satisfied & $26(44.1)$ \\
$\begin{array}{c}\text { Children } \\
(\mathrm{n}=59)\end{array}$ & Satisfied & $14(23.7)$ \\
& Normal & $17(28.8)$ \\
& Not satisfied & $2(3.4)$ \\
Teacher & Very satisfied & $1(33.3)$ \\
$(\mathrm{n}=3)$ & Satisfied & $2(66.7)$ \\
$\ldots \ldots \ldots \ldots \ldots \ldots \ldots \ldots$ & $24(44.1)$ \\
Parent & Very satisfied & $31(23.7)$ \\
$(\mathrm{n}=57)$ & Satisfied & $2(28.8)$ \\
\hline
\end{tabular}

Installing biowalls to serve as natural elements in a classroom environment significantly improved the children's emotional and behavioral development after 3 months. These encouraging effects, such as increased emotional intelligence, were likely due to children's direct/indirect contact with the natural elements. Direct contact (i.e., observing or touching the plants on the biowalls) included the children experiencing a variety of emotional exercises, which positively influenced the development of emotional intelligence (Coel et al., 2009). Also, these installations changed the physical environment, which encouraged children to interact with the environment, providing them an external stimulus. Notably, closely interacting with natural elements not only may improve social behaviors but also can enhance interactions between individuals, which may be a critical factor in the development of children's emotional intelligence (Mirrahimi et al., 2011). When considering the developmental process of children in preschool, imagery and sensation-based stimuli may serve as alternative tools for encouraging children to recognize and express a diversity of feelings (Brechet, 2017). Thus, having a biowall in a classroom may serve as a simple and naturally effective stimulus for the children that can help them express their emotions about nature or natural elements.

Previous studies also reported that direct/indirect contact with natural elements positively affected children's' emotional intelligence (Balseviciene et al., 2014; Lee et al., 2020; Park et al., 2016). For example, a previous study investigated the increased emotional intelligence of 336 children between the ages of five and seven who practiced direct contact with nature by growing plants. Balseviciene et al. (2014) investigated the emotions and behaviors that were affected by having opportunities to experience indirect contact with nature. By observing over 1,468 preschool children between the ages of four and six, they found that preschool children show superior peer relations and sociable behaviors - indicating that they are emotionally stable-if they live in a residential environment that exposes them to nature more frequently.

As the children went about their daily routine in a classroom that contained the new biowall, their enhanced resilience may have derived from them experiencing nature's buffering effects (Wells and Evans, 2003). Contributing to 
their sense of resilience, this protective response results from the impact of experiencing close contact with nature, either directly or indirectly. Since the biowalls bring natural elements into the classroom environment, the children assumedly had more opportunities to experience close contact with nature. Thus, we could anticipate (to a certain extent) nature's buffering effects in a classroom setting that contained a biowall, a natural element that exposes children to nature. The buffer provided by the biowall eases the potential effects of stress and adversity on the children (Wells and Evans, 2003).

Previous studies also reported increased resilience and emotional stability after having contact with green plants and nature (Amoly et al., 2014; Flouri et al., 2014; S.O. Kim et al., 2020; Wells and Evans, 2003). For example, S.O. Kim et al. (2020) conducted a study through the lens of psycho-physiology, which demonstrates that the installation of green plants in a learning environment may lead to improved concentration and emotional stability. This conclusion was supported by increased theta-waves in the brain activity of nine-year-old children. Wells and Evans (2003) examined the relationship between resilience and the frequency of exposure to nature by utilizing 337 children as participants. The relationship was positive, which means that if children live in a residential environment that gives them more exposure to nature, they have a superior chance of demonstrating more resilience and self-esteem, a finding which is also comparable to those of the current study.

The improvements in children's eco-friendly attitude 3 months after the biowalls' installation may have been influenced by having nature near their living space, connecting them to it on a more intimate level. Since this study aimed to encourage this connection and instigate contact with nature by providing it in their living space for 3 months, the children may have generated a stronger relationship with nature (Mayer and Frantz, 2004). Therefore, biophilic design (e.g., the installation of biowalls in classrooms) may be a medium or tool for teaching children about environmental education (Cole et al., 2013; Cole, 2014; Tucker and Izadpanahi, 2017).

Previous studies also reported that individuals who live in green spaces or green buildings more easily connect to nature and demonstrate an enhanced eco-friendly mindset/conduct (Azizi et al., 2015; Wu et al., 2013). For example, Wu et al. (2013) conducted a study on 61 college students and found that those who attended a 'green' school were more likely to recycle their waste, as compared to students who attended a conventional campus. Notably, Cheng and Monroe (2012) reported that having a connection to nature near one's home has a strong positive correlation with developing an interest in environmentally conscious practices, to the extent that it can even be utilized as a predictor. Thus, these studies also support our results and findings, as positive perceptions toward nature facilitate an eco-friendly attitude (Corraliza and Collado, 2019).

\section{Conclusion}

The present study demonstrates that installing biowalls in classroom environments at the kindergarten level positively affects children's emotional development and health over a period of 3 months. Biowalls bring natural elements into indoor classroom settings, which provides a physical environment that exposes children to increased direct/indirect contact with nature.

However, this study has limitations, as the design did not exclude the potential for children's maturation over the course of the experiment and the influence of other environmental factors. To differentiate the maturation effects of the fast-growing children, a complete experimental design with control groups should be adopted in future studies. Also, the subject group should be broader, and the space of the studies be directed toward larger audiences. These efforts will further elucidate the various beneficial effects of biowalls in indoor environments.

\section{References}

Amoly, E., P. Dadvand, J. Forns, M. López-Vicent e, X. Basagaña, J. Julvez, M. Alvarez-Pedrerol, M.J. Nieuwenhuijsen, and J. Sunyer. 2014. Green and blue spaces and behavioral development in Barcelona schoolchildren: The BREATHE Project. Environ. Health Perspect. 
122(12):1351-1358. https://doi.org/10.1289/ehp.1408215

Azizi, N.S.M., S. Wilkinson, and E. Fassman. 2015. An analysis of occupants response to thermal discomfort in green and conventional buildings in New Zealand. Energy Build. 104:191-198. https://doi.org/10.1016/j.en build.2015.07.012

Bailie, P.E. 2010. From the one-hour field trip to a nature preschool: Partnering with environmental organizations. Young Child. 65(4):76-82.

Balseviciene, B., L. Sinkariova, R. Grazuleviciene, S. Andrusaityte, I. Uzdanaviciute, A. Dedele, and M.J. Nieuwenhuijsen. 2014. Impact of residential greenness on preschool children's emotional and behavioral problems. Int. J. Environ. Res. Public Health. 11:6757-6770. https://doi.org/10.3390/ijerph110706757

Brechet, C. 2017. Children's recognition of emotional facial expressions through photographs and drawings. J. Genet. Psychol. 178:139-146. https://doi.org/10.1080/0022132 5.2017.1286630

Cheng, J.C.H. and M.C. Monroe. 2012. Connection to nature: Children's affective attitude toward nature. Environ. Behav. 44:31-49. https://doi.org/10.1177/001391651038 5082

Choi, J.Y., S.A. Park, S.J. Jung, J.Y. Lee, K.C. Son, Y.J. An, and S.W. Lee. 2016. Physiological and psychological responses of humans to the index of greenness of an interior space. Complement. Ther. Med. 28:37-43. https://doi.org/10.1016/j.ctim.2016.08.002

Coel, M., S.R. Cole, and C. Lightfoot. 2009. The development of children. New York, USA: Worth Publishers.

Cole, L.B. 2014. The teaching green school building: A framework for linking architecture and environmental education. Environ. Educ. Res. 20(6):836-857. https://do i.org/10.1080/13504622.2013.833586

Cole, R.J. and M.J. Valdebenito. 2013. The importation of building environmental certiication systems: International usages of BREEAM and LEED. Build. Res. Inf. 41:662-676. https://doi.org/10.1080/09613218.2013.802115

Collado, S. and H. Staats. 2016. Contact with nature and children's restorative experiences: an eye to the future. Front. Psychol. 7:1885. https://doi.org/10.3389/fpsyg.20 16.01885

Corraliza, J.A. and S. Collado. 2019. Ecological awareness and children's environmental experience. Papeles del Psicólogo 3:190-196. https://doi.org/10.23923/pap.psico 12019.2896

Daly, J., M. Burchett, and F. Torpy. 2010. Plants in the classroom can improve student performance. University of Technology, Sydney, Australia. Retrieved from www. wolvertonenvironmental.com/Plants-Classroom.pdf.

Deng, L. and Q. Deng. 2018. The basic roles of indoor plants in human health and comfort. Environmental Sci. Pollut. Res. 25:36087-36101. https://doi.org/10.1007/s11356-0 18-3554-1

Doxey, J.S., T.M. Waliczek, and J.M. Zajicek. 2009. The impact of interior plants in university classrooms on student course performance and on student perceptions of the course and instructor. HortScience. 44(2):384-391. https://doi.org/10.21273/HORTSCI.44.2.384

Egeland, B.R., E. Carlson, and L.A. Sroufe. 1993. Resilience as process. Dev. Psychopathol. 5(4):517-528. https://doi. org/10.1017/S0954579400006131

Evans, G.W. 2006. Child development and the physical environment. Annual review of Psychology 57:423-451. https://doi.org/10.1146/annurev.psych.57.102904.190057

Ferguson, K.T., R.C. Cassells, J.W. MacAllister, and C.W. Evans. 2013. The physical environment and child development: An international review. Int. J. Psychol. 48: 437-468. https://doi.org/10.1080/00207594.2013.804190

Flouri, E., E. Midouhas, and H. Joshi. 2014. The role of urban neighbourhood green space in children's emotional and behavioural resilience. J. Environ. Psychol. 40:179-186. https://doi.org/10.1016/j.jenvp.2014.06.007

Gillis, K. and B. Gatersleben. 2015. A review of psychological literature on the health and wellbeing benefits of biophilic design. Buildings. 5:948-963. https://doi.org/10.3390/buildings5030948

Hofferth, S.L. 2009. Changes in American children's time: 1997 to 2003. Electron. Int. J. Time Use Res. 6:26-47.

Howell, A.J., H.A. Passmore, and K. Buro. 2013. Meaning in nature: Meaning in life as a mediator of the relationship between nature connectedness and well-being. J Ha ppiness Stud. 14:1681-1696. https://doi.org/10.1007/s10 902-012-9403-x

Hur, Y.J. 2001. The effect of integrated activities for forstering animals on the children's proenvironmental 
attitudes. Master's Thesis, Chung-Ang University, Seoul, Korea.

Kahn, P.H., and S.R. Kellert. 2002. Experiencing nature: Affective cognitive and evaluative development in children. In S.R. Kellert (Ed), Children and nature: Psychological sociocultural and evolutionary investigations (pp. 117-151). Cambridge, MA: MIT Press.

Kim, H.H., I.Y. Yeo, and J.Y. Lee. 2020. Higher attention capacity after improving indoor air quality by indoor plant placement in elementary school classrooms. Hort. J. 89(3):319-327. https://doi.org/10.2503/hortj.UTD-110

Kim, S.O., Y.A. Oh, and S.A. Park. 2020. Foliage plants improve concentration and emotional condition of elementary school students performing an intensive assignment. HortScience. 55(3):378-385. https://doi.org/10.21273/H ORTSCI14757-19

Korpela, K. 2002. Children's environments. In R. B. Bechtel, and A. Churchman (Eds.); Handbook of environmental psychology (pp. 363-373). New York, NY: John Wiley.

LeBuffe, P.A.and J.A. Naglieri. 1999. The devereux early childhood assessment. Lewisewille, North Carolina: Kaplan Press.

Lee, A.Y., S.O. Kim, G.M. Gim, D.S. Kim, and S.A. Park. 2020. Care farming program for family health: A pilot study with mothers and children. Int. J. Environ. Res. Public Health 17(1):27. https://doi.org/10.3390/ijerph17 010027

Lee, B.N. 2005. The relationship between kindergartners' emotional intelligence and their mothers' perfectionism. Early Child. Educ. Res. Rev. 9(4):277-294.

Lee, W.J. 2002. Resilience and protective factors in at risk children. Korean J. Child. Stud. 23(1):1-16.

Leung, M.Y. and I. Fung. 2005. Enhancement of classroom facilities of primary schools and its impact on learning behaviors of students. Facilities. 23:585-594. https://doi.org/10.1108/02632770510627561

Manso, M. and J. Castro-Gomes. 2015. Green wall systems: A review of their characteristics. Renew. Sustain. Energy Rev. 41:863-871. https://doi.org/10.1016/j.rser.2014.07. 203

Mayer, F.S., and C.M. Frantz. 2004. The connectedness to nature scale: A measure of individuals' feeling in community with nature. J. Environ. Psychol. 24(4): 503-515. https://doi.org/10.1016/j.jenvp.2004.10.001

Mirrahimi, S., N.M. Tawil, N.A.G. Abdullah, M., Surat, and I.M.S. Usman. 2011. Developing conducive sustainable outdoor learning: The impact of natural environment on learning, social and emotional intelligence. Procedia Eng. 20:389-396. https://doi.org/10.1016/j.proeng.2011. 11.181

Moore, R.C. 1986. Childhood's domain. London, UK: Croom Helm.

Mullan, K. 2019. A child's day: trends in time use in the UK from 1975 to 2015. Br. J. Sociol. 70:997-1024. https://doi.org/10.1111/1468-4446.12369

Musser, L.M., and K.E. Diamond. 1999. The children's attitudes toward the environment scale for preschool childre n. J. Environ. Educ. 30(2):23-30. https://doi.org/10.1080 /00958969909601867

National Institute of Biological Resources. 2018. The mass proliferation of wild plants and community governance (1) (Report No, NIBR 201820101), Incheon, Korea. Retrieved from https:/ecolibrary.me.go.kr/nibr/\#/search /detail/5671856

Natural England. 2016. Feb. 10. Monitor of engagement with the natural environment: A pilot to develop an indi cator of visits to the natural environment by children a pilot for an indicator of visits to the natural environme nt by children. Natural England, York, UK. Retrieved from https://www.gov.uk/government/statistics/monitorof-engagement-with-the-natural-environment-pilot-stud y-visits-to-the-natural-environment-by-children (accesse d on 30 May 2020).

Park, S.A., M.K. Cho, M.H. Yoo, S.Y. Kim, E.A. Im, J.E. Song, J.C. Lee, and I.G. Jun. 2016. Horticultural activity program for improving emotional intelligence, prosocial behavior, and scientific investigation abilities and attitudes in kindergarteners. HortTechnology. 26(6);754-761. https://doi.org/10.21273/HORTTECH03489-16

Park, S.Y., J.S. Song, H.D. Kim, K. Yamane, and K.C. Son. 2008. Effects of interior plant scapes on indoor environments and stress level of high school students. Hort. J. 77(4):447-454. https://doi.org/10.2503/jjshs 1.7 7.447

Pegas, P.N., C. Alves, T. Nunes, E. Bate-Epey, M. Evtyugina, and C.A. Pio. 2012. Could houseplants improve indoor 
air quality in schools?. J. Toxicol. Environmental. Heal. A 75:1371-1380. https://doi.org/10.1080/15287394.201 2.721169

Phenice, L.A., and R.J. Griffore. 2003. Young children and the natural world. Contemp. Issues Early Child. 4:167-171. https://doi.org/10.2304/ciec.2003.4.2.6

Salovey, P. and J.D. Mayer. 1990. Emotional intelligence. Imagin. Cogn. Pers. 9:185-211. https://doi.org/10.2190/ DUGG-P24E-52WK-6CDG

Tucker, R. and P. Izadpanahi. 2017. Live green, think green: Sustainable school architecture and children's environmental attitudes and behaviors. J. Environ. Psychol. 51:209-216. https://doi.org/10.1016/j.jenvp.2017.04.003

van den Berg, A.E., J.E. Wesselius, J. Maas, and K. Tanja-Dijkstra. 2017. Green walls for a restorative classroom environment: A controlled evaluation study. Envir on. Behav. 9:791-813. https://doi.org/10.1177/00139165 16667976

van den Bogerd, N., S.C. Dijkstra, K. Tanja-Dijkstra, M.R. de Boer, J.C. Seidell, S.L. Koole, and J. Maas. 2020. Greening the classroom: Three field experiments on the effects of indoor nature on students' attention, well-being, and perceived environmental quality. Build. Environ. 171:106675. https://doi.org/10.1016/j.buildenv.2020.10 6675

Wells, N.M. and G.W. Evans. 2003. Nearby nature: A buffer of life stress among rural children. Environ. Behav. 35(3):311-330. https://doi.org/10.1177/0013916 503035003001

Wu, D.W.L., A. DiGiacomo, A. Kingstone. 2013. A sustainable building promotes pro-environmental behavior: an observational study on food disposal. PloS One. 8(1): e53856. https://doi.org/10.1371/journal.pone.0053856

Yoon, H., S.K. Yoo, J. Seo, T. Kim, P. Kim, P.J. Kim, J. Park, J. Heo, and W. Yang. 2020. Development of general exposure factors for risk assessment in Korean children. Int. J. Environ. Res. Public Health. 17(6):1988. https://doi.org/10.3390/ijerph17061988

Zhang, W., E. Goodale, and J. Chen. 2014. How contact with nature affects children's biophilia, biophobia and conservation attitude in China. Biol. Conserv. 177:109-116. https://doi.org/10.1016/j.biocon.2014.06.011 